\section{A) Check for updates}

Cite this: Dalton Trans., 2021, 50 12923

Received 5th June 2021 Accepted 26th July 2021 DOI: $10.1039 / \mathrm{d} 1 \mathrm{dt} 01839 f$ rsc.li/dalton

\title{
Reversible single-crystal to single-crystal phase transformation between a new Werner clathrate and its apohost $\uparrow$
}

\author{
Catiúcia R. M. O. Matos, (DD a,b Rana Sanii, (D) a Shi-Qiang Wang, (D) a \\ Célia M. Ronconi (D) ${ }^{b}$ and Michael J. Zaworotko (D)*a
}

\begin{abstract}
In this work, we report the synthesis and structural characterisation of the ligand 2-(pyridin-3-yl)-benzo [de]isoquinoline-1,3(2H)-dione, 5, its isostructural Werner complexes $\mathrm{ML}_{4}(\mathrm{NCS})_{2}(\mathrm{~L}=\mathbf{5} ; \mathrm{M}=\mathrm{Co}(I)$ and $\mathrm{Ni}$ $\left(\right.$ II)), and five clathrates with three aromatic guests, $\mathrm{ML}_{4}(\mathrm{NCS})_{2} \cdot 2 \mathrm{G}(\mathrm{M}=\mathrm{Co}(\|)$ and $\mathrm{Ni}(\|), \mathrm{G}=$ nitrobenzene $(\mathrm{NB}) ; \mathrm{M}=\mathrm{Co}, \mathrm{G}=1,2$-dichlorobenzene (1,2-DCB); $M=\mathrm{Co}(\Perp)$ and $\mathrm{Ni}(\|), \mathrm{G}=0$-xylene $(\mathrm{OX})) .5$ was prepared in high yield by condensation in the solid-state $\left(\mathrm{C}^{3} \mathrm{~S}^{3}\right.$, Cocrystal Controlled Solid-State Synthesis). The Werner complexes $\mathrm{ML}_{4}(\mathrm{NCS})_{2}\left(\mathrm{M}=\mathrm{Co}(\|)\right.$ and $\left.\mathrm{Ni}\left({ }^{\prime \prime}\right)\right)$ (apohosts) were prepared by reacting $\mathrm{M}(\mathrm{NCS})_{2}(\mathrm{M}$ $=\mathrm{Co}(॥)$ and $\left.\mathrm{Ni}\left({ }^{\prime \prime}\right)\right)$ and 5 in 1-butanol at $60^{\circ} \mathrm{C}$ for $24 \mathrm{~h}$. The Werner clathrates were prepared by reacting $\mathrm{M}(\mathrm{NCS})_{2}(\mathrm{M}=\mathrm{Co}(॥)$ and $\mathrm{Ni}(\Perp)), \mathrm{G}$ and 5 in 1 -butanol at $60^{\circ} \mathrm{C}$ for $48-96 \mathrm{~h}$. The clathrates were observed to transform to the apohost $\mathrm{ML}_{4}(\mathrm{NCS})_{2}$ upon heating. $\mathrm{CoL}_{4}(\mathrm{NCS})_{2} \cdot 2 \mathrm{NB}$ was subsequently regenerated by exposing $\mathrm{CoL}_{4}(\mathrm{NCS})_{2}$ to liquid $\mathrm{NB}$ at $60{ }^{\circ} \mathrm{C}$ for $48 \mathrm{~h}$. This phase change occurred as a single-crystal to single-crystal phase transformation and was studied by single crystal X-ray diffraction, powder X-ray diffraction and thermal analyses. Structural analyses of the apohost $\mathrm{CoL}_{4}(\mathrm{NCS})_{2}$ and its Werner clathrate $\mathrm{CoL}_{4}(\mathrm{NCS})_{2} \cdot 2 \mathrm{NB}$ indicated that rotational freedom of the Co-N bonds together with torsional flexibility of the ligand between the imide bond and the pyridine moiety are key to enabling the structural switching induced by exposure to NB or its removal.
\end{abstract}

\section{Introduction}

Werner complexes of general formula $\mathrm{ML}_{4} \mathrm{X}_{2}$ are historically important in the context of coordination chemistry ${ }^{1}$ and are exemplified by octahedral transition metal (M) complexes that involve coordination of four equatorial aromatic $\mathrm{N}$-donor ligands (L) and two axial anionic ligands (X). Powell introduced the concept of "clathrate" in the 1940s to classify compounds in which guest molecules are trapped within a void present in the structure of host compound. ${ }^{2,3}$ By the late 1950 s it had been recognised that Werner complexes can form clathrates of general formula $\mathrm{ML}_{4} \mathrm{X}_{2} \cdot n \mathrm{G}$ ( $\mathrm{G}=$ guest). ${ }^{4-6}$ Schaeffer

\footnotetext{
${ }^{a}$ Department of Chemical Sciences, Bernal Institute, University of Limerick, Limerick V94 T9PX, Republic of Ireland. E-mail: Michael.Zaworotko@ul.ie ${ }^{b}$ Department of Inorganic Chemistry, Universidade Federal Fluminense (UFF), Outeiro de São João Batista, s/n, Campus do Valonguinho, Centro, 24020-141 Niterói, RJ, Brazil

$\dagger$ Electronic supplementary information (ESI) available: Complete synthetic protocol, compound characterisation and crystallographic details. CCDC 1995785-1995796 and 2065192. For ESI and crystallographic data in CIF or other electronic format see DOI: 10.1039/d1dt01839f
}

reported that the Werner complex $\mathrm{Ni}(4-\mathrm{MePy})_{4}(\mathrm{NCS})_{2},(4-\mathrm{MePy}$ = 4-methylpyridine) forms clathrates with xylenes, cymenes and methylnaphthalenes and that selective clathration enables separation of aromatic hydrocarbons. ${ }^{4}$ Several other groups subsequently studied the inclusion chemistry of Werner complexes. Radzitzk investigated Werner complexes containing a variety of primary substituted benzylamine ligands, e.g. $\mathrm{Ni}(\alpha \text {-propylbenzylamine })_{4}(\mathrm{NCS})_{2}$, and their selective clathration of mono- and poly-substituted benzenes and naphthalenes. ${ }^{5}$ Williams studied the clathrates of $\mathrm{M}(4$ $\mathrm{MePy})_{4}(\mathrm{NCS})_{2}(\mathrm{M}=\mathrm{Fe}, \mathrm{Co}, \mathrm{Ni})$ formed in the presence of mixtures of dichlorobenzenes or methylstyrenes and observed selectivity towards the respective para isomers. ${ }^{6}$ In the $1980 \mathrm{~s}$, Lipkowski detailed how $\mathrm{Ni}(4-\mathrm{MePy})_{4}(\mathrm{NCS})_{2}$ forms clathrates with 1-bromonaphthalene and azulene. ${ }^{7}$ Lipkowski's group also studied clathrate formation in terms of kinetics and thermodynamic stability for $\mathrm{Ni}(4-\mathrm{MePy})_{4}(\mathrm{NCS})_{2} \cdot{ }^{8}$ The term "Werner clathrate" was coined by Nassimbeni and co-workers in the $1980 \mathrm{~s},{ }^{9-12}$ who explored the versatility of $\left[\mathrm{Ni}(\mathrm{NCS})_{2}(4-\right.$ $\left.\mathrm{MePy})_{4}\right]$ complexes through substitution of the pyridine ligands and/or counterions and their clathrates with xylenes and other guests. ${ }^{13,14}$ 
The porous (open) phases of the Werner clathrates are typically crystallised by forming a Werner complex in the presence of guest molecules or through exposure of an as-synthesised non-porous (closed) Werner complex to solid-liquid and/or solid-vapour reactions with guests. ${ }^{15}$ The inclusion of guest molecules within the structures of Werner clathrates can be classified into four categories according to their crystal packing motifs: (i) densely packed non-porous, $\alpha$-phase; (ii) porous $\beta$-phase, a cage-type clathrate; (iii) porous $\delta$-phase, a channel-type clathrate and (iv) porous $\gamma$-phase, a layer-type clathrate. ${ }^{10,16,17}$

An important feature of Werner complexes is the rotational freedom of metal-N bonds. ${ }^{11}$ For substituted pyridine ligands there can be additional rotational freedom for the Werner complex thanks to torsional flexibility at the substituent. ${ }^{13,18}$ In essence, this is what enables a Werner complex to adjust its shape to accommodate a variety of guests of different sizes and shapes ${ }^{11}$ while also facilitating the reverse phase transformation through removal of guest molecules. The potential utility of Werner complexes in separations is critically dependent upon both the selectivity of Werner clathrates towards the components of a mixture and whether or not guest uptake/ removal is reversible. ${ }^{19-27}$

A survey of the literature has revealed that some Werner complexes can exhibit reversible sorption isotherms between their non-porous and porous phases. We recently termed such complexes Switching Adsorbent Molecular Materials (SAMMs). ${ }^{15,16,28,29}$ Structural switching between non-porous and porous phases in SAMMs is demonstrated by a single-step or "Type F-IV" ticular interest because which can offer higher working capacities than rigid porous materials, which tend to exhibit Type I isotherms. ${ }^{31,32}$ To our knowledge, the first reversible sorption isotherm for a Werner complex was reported in 1969 by Allison and Barrer, ${ }^{31}$ who investigated the sorption properties of Co(4-ethylpyridine $)_{4}(\mathrm{NCS})_{2}$, SAMM-1-Co-NCS, when exposed to benzene, toluene or C8 isomer. ${ }^{31}$ SAMM-2-Cu-PF 6 ( 2 = 4-methylpyridine) was studied by Nakamura et $a l^{28}$ and found to form clathrates with guests such as acetone, butanone and benzene. Sorption isotherms were reported for benzene and $\mathrm{CO}_{2}$. Nakamura et al. also reported on SAMM-4$\mathbf{C u}-\mathbf{P F}_{\mathbf{6}}$ and $\mathbf{S A M M - 4 - C u - \mathbf { B F } _ { \mathbf { 4 } }}$ (4 = pyridine) and their acetone and acetonitrile vapour sorption isotherms. ${ }^{29}$ Barbour et al. studied SAMM-3-Ni-NCS ( 3 = 4-phenylpyridine) and its clathrates with $o$-xylene (OX), $p$-xylene (PX) and $m$-xylene (MX). SAMM-3-Ni-NCS was found to exhibit the highest selectivity observed for the three xylene isomers at that time. ${ }^{16}$ Sorption isotherms of benzene and toluene were also reported. ${ }^{16}$ Recently, we reported that SAMM-3-Cu-OTf switches between non-porous and porous phases upon exposure to OX but not when exposed to other C8 isomers at high partial pressure. ${ }^{33}$

That Werner complexes and related materials, such as flexible porous coordination networks, can exhibit selective capture of organic compounds ${ }^{34,35}$ is a topical subject thanks to the lack of scientific understanding about what drives switching phenomena and the potential utility for separations.
With respect to coordination networks, we and others ${ }^{36-40}$ have demonstrated that square lattice topology coordination networks based upon Werner complexes connected by linker ligands ${ }^{41}$ can exhibit reversible phase transformations when exposed to a range of guests. In addition, metal complexes that undergo structural switching and reversible isotherms triggered by a guest molecule remain quite rare. A survey of the Cambridge Structural Database (CSD, ConQuest 2020 2.0,

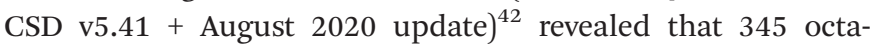
hedral metal complexes containing pyridine-based terminal ligands are archived but only six are SAMMs that are known to exhibit reversible clathrate formation (CSD database search details, ESI $\dagger$ ). SAMMs based upon Werner complexes therefore remain an understudied class of compounds and represent an attractive platform for structure-function studies thanks in part to the ready availability of many N-donor ligands that in turn allow for creation of families of closely related complexes. In addition, we note that Werner complexes offer synthetic simplicity and structural diversity in comparison to most coordination networks. Our specific interest in the study of Werner complexes lies with properties, especially the study of Werner complexes that exhibit pore adaptive behaviour that can result in selectivity towards a specific guest. ${ }^{32,33}$ Such behaviour opens the opportunity to generate high working capacity sorbents for selective separation by enclathration.

In this contribution, we report the solid-state synthesis 2(pyridin-3-yl)-benzo[de]isoquinoline-1,3(2H)-dione, 5, and its use as a Werner complex ligand. The formation of imides from Cocrystal Controlled Solid-State Synthesis $\left(\mathrm{C}^{3} \mathrm{~S}^{3}\right)$ has been previously exploited by our group as a mechanochemical approach to prepare ligands ${ }^{43-45}$ and typically involves solventdrop grinding (SDG) ${ }^{46-48}$ followed by heating. Advantages of $\mathrm{C}^{3} \mathrm{~S}^{3}$ include the following: (i) little solvent is required, especially compared to solution-based synthesis methods; (ii) yields are typically high, often approaching quantitative; (iii) new condensation products can be readily accessible from simple organic building blocks. ${ }^{49}$

\section{Results and discussion}

\section{Synthesis of ligand 5}

(2-(Pyridin-3-yl)-1H-benzo[de]isoquinoline-1,3(2H)-dione), 5, was previously reported as an intermediate of an $\mathrm{N}$-oxide organic ligand obtained by microwave-assisted synthesis ${ }^{50}$ and has been used to form $\mathrm{Eu}(\mathrm{III}), \mathrm{Gd}(\mathrm{III})^{50}$ and $\mathrm{Ru}(\mathrm{II})$ complexes $^{51}$ but is otherwise unstudied. We prepared 5 from condensation of 1,8-naphthalene anhydride (1,8-NA) and the 3-amino-pyridine (3APy) using $\mathrm{C}^{3} \mathrm{~S}^{3}$ (Fig. 1a). ${ }^{43,44}$ A $1: 1$ ground mixture of 1,8-NA and $3 \mathrm{APy}$ formed an intermediate via SDG when using $120 \mu \mathrm{L}$ of EtOH. The imide was obtained by heating the intermediate at $185^{\circ} \mathrm{C}$ for $5 \mathrm{~h}$, affording 5 in $93 \%$ yield (Fig. 1a). In the synthesis of $\mathbf{5}$, the selection of EtOH was guided by solvent selection guidelines developed by and for industry. ${ }^{52}$ To our knowledge, the synthesis of $\mathbf{5}$ through mechanochemistry has not been previously reported. 


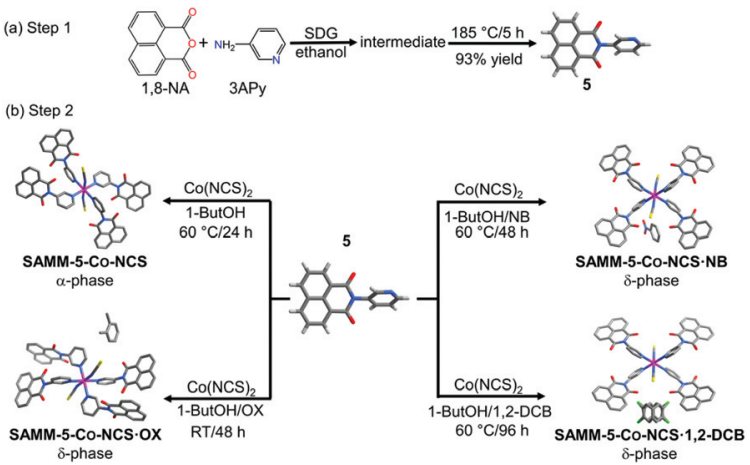

Fig. 1 (a) Synthesis of 5 was accomplished using Cocrystal Controlled Solid-State Synthesis $\left(C^{3} S^{3}\right)$ approach via solvent-drop grinding (SDG). (b) Preparation of SAMM-5-Co-NCS and its Werner clathrates with nitrobenzene, NB, SAMM-5-Co-NCS-NB; o-xylene, OX, SAMM-5-Co-NCS-OX and 1,2-dichlorobenzene, 1,2-DCB, SAMM-5-Co-NCS·(1,2-DCB).

\section{Synthesis of Werner complexes and clathrates}

5 and $\mathrm{M}(\mathrm{NCS})_{2}(\mathrm{M}=\mathrm{Co}(\mathrm{II})$ and $\mathrm{Ni}(\mathrm{II}))$ were dissolved by heating in 1-butanol or 1-butanol/MeOH and layered to form the Werner complexes reported herein. Reaction of 5 with Co $(\mathrm{NCS})_{2}$ in 1-butanol at $60{ }^{\circ} \mathrm{C}$ afforded pink crystals of the apohost, SAMM-5-Co-NCS (Fig. 1b, 3a, b and Scheme S1†), whereas reaction with $\mathrm{Ni}(\mathrm{NCS})_{2}$ in 1-butanol/MeOH afforded green crystals of SAMM-5-Ni-NCS (Scheme S1 $\dagger$ ). SAMM-5-NiNCS was also obtained from heating the Werner clathrates of Ni(II) with OX and NB.(Fig. S17a and b†) Reaction of 5 with $\mathrm{M}(\mathrm{NCS})_{2}(\mathrm{M}=\mathrm{Co}(\mathrm{II})$ or $\mathrm{Ni}(\mathrm{II}))$ in $\mathrm{NB}$ with 1-butanol or 1-butanol/MeOH, afforded the isostructural Werner clathrates SAMM-5-Co-NCS·NB and SAMM-5-Ni-NCS·NB as pink and green crystals, respectively (Fig. 1b, 3c, d, S17c, d and Scheme $\mathrm{S} 1 \dagger)$. A detailed description of the structure of SAMM-5-Co-NCS·NB is presented below.

Reaction of 5 and $\mathrm{Co}(\mathrm{NCS})_{2}$ in a mixture of 1-butanol and 1,2-DCB formed SAMM-5-Co-NCS·(1,2-DCB) as pink crystals suitable for SCXRD (Fig. 1b, 3e, f and Scheme S1 $\dagger$ ). Reaction of 5 with $\mathrm{M}(\mathrm{NCS})_{2}(\mathrm{M}=\mathrm{Co}(\mathrm{II})$ or $\mathrm{Ni}(\mathrm{II}))$ in a mixture of $\mathrm{OX}$, 1-butanol or 1-butanol/MeOH afforded the isostructural Werner clathrates SAMM-5-Co-NCS-OX and SAMM-5-NiNCS.OX (Fig. 1b, 3g, h and Scheme S1†). Only the structural details of SAMM-5-Co-NCS.OX are discussed in detail herein. Our initial attempts to obtain Werner clathrates using OX at $60{ }^{\circ} \mathrm{C}$ for $48 \mathrm{~h}$ afforded SAMM-5-Co-NCS and SAMM-5-Ni-NCS with some crystals of SAMM-5-Co-NCS-OX and SAMM-5-NiNCS·OX, respectively (Fig. S9a $\dagger$ ). However, reactions at room temperature for $48 \mathrm{~h}$ resulted in the formation of the clathrate phases SAMM-5-Co-NCS.OX and SAMM-5-Ni-NCS·OX as bulk products (Fig. S9b $\dagger$ ). Attempts to obtain Werner clathrates at $60{ }^{\circ} \mathrm{C}$ using ethylbenzene (EB), methylnaphthalene (MN), meta-xylene (MX) and para-xylene (PX) were unsuccessful and resulted instead in isolation of SAMM-5-Co-NCS. SAMM-5-CoNCS.EB was obtained at room temperature and found to be isostructural with SAMM-5-Co-NCS-OX. Full characterisation details are provided in ESI. $\dagger$

\section{Structural analyses}

SCXRD studies revealed that $\mathbf{5}$ crystallised as an anhydrate in the orthorhombic space group $P 2_{1} 2_{1} 2_{1}$ with one molecule of 5 comprising the asymmetric unit (Fig. 2a and Table S2, ESI $\dagger$ ). The torsional flexibility of the imide bond allowed for the pyridyl ring to be twisted by $55.42^{\circ}$ and $-126.56^{\circ}$ (torsion angles) with respect to the imide moiety. A number of $\mathrm{CH} \cdots \pi$, $\mathrm{CH} \cdots \mathrm{N}$ and $\mathrm{CH} \cdots \mathrm{O}$ contacts, $\pi \cdots \pi$ stacking directed the crystal packing (Fig. 2b).

SAMM-5-Co-NCS crystallised in the monoclinic space group $P 21 / n$ (Table S3 and Fig. S17a and b, ESI $\dagger$ ) with two crystallographically independent molecules of 5 , one $\mathrm{Co}^{2+}$ cation on a special position, and one independent $\mathrm{NCS}^{-}$anion comprising the asymmetric unit (Fig. S13a, ESI $\dagger$ ). The crystal structure of SAMM-5-Co-NCS revealed that each $\mathrm{Co}^{2+}$ cation adopts octahedral coordination geometry with nitrogen atoms from four different ligands forming the equatorial plane and $\mathrm{Co}-\mathrm{N}$ bond distances ranging from 2.218(6) to 2.293(7) A. Octahedral coordination is completed by two $\mathrm{NCS}^{-}$anions at the axial positions of the $\mathrm{Co}^{2+}$ with $\mathrm{Co}-\mathrm{N}$ bond distances of 2.055(9) $\AA$ (Fig. 3a). These distances are in good agreement with related coordination compounds. ${ }^{53-55}$ As mentioned earlier, Werner complexes and clathrates can be classified into four categories, $\alpha, \beta, \delta$ or $\gamma$, according to the type of crystal packing. ${ }^{10,16,17}$ SAMM-5-Co-NCS and SAMM-5-Ni-NCS are therefore classified as $\alpha$-phases since they are densely-packed and non-porous (Fig. 3a, b and Fig. S17a, $\mathrm{b} \dagger$ ) ${ }^{10}$ Intermolecular interactions include $\mathrm{CH} \cdots \pi, \mathrm{CH} \cdots \mathrm{N}$ and $\mathrm{CH} \cdots \mathrm{O}$ contacts along with $\pi \cdots \pi$ stacking (Table S5, ESI $\dagger$ ).

SAMM-5-Co-NCS·NB crystallised in the monoclinic space group $P 2_{1} / n$, whereas SAMM-5-Co-NCS-OX adopted the triclinic space group $P \overline{1}$ (Fig. 3c, g, S17, S18, Tables S3 and S6, ESI $\dagger$ ). The asymmetric unit of each Werner clatharate contains two crystallographically independent molecules of 5 , one $\mathrm{Co}^{2+}$ cation at a special position, one coordinated $\mathrm{NCS}^{-}$anion and one guest molecule (NB or OX) (Fig. S13, ESI $\dagger$ ). The octahedral geometries around $\mathrm{Co}^{2+}$ are retained in SAMM-5-Co-NCS·NB and SAMM-5-Co-NCS.OX, with Co-N bond distances ranging from 2.055 (18) to 2.213(19) A. The structural analysis revealed that NB or OX molecules lie in channels of SAMM-5-CoNCS·NB and SAMM-5-Co-NCS-OX, respectively, classifying them as porous $\delta$-phases (Fig. $3 \mathrm{~d}$ and $\mathrm{h}$ ). The rotational freedom about $\mathrm{Co}-\mathrm{N}$ bonds, as well as the flexibility between the imide bond and the pyridine moiety of $\mathbf{5}$, provided two dis- (a)

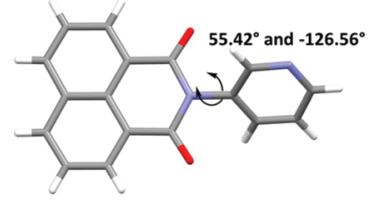

(b)

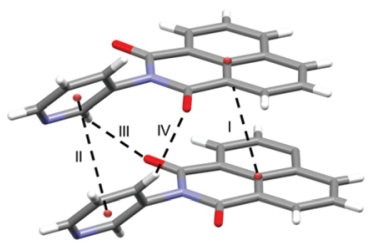

Fig. 2 (a) Asymmetric unit of 5 and its torsion angles. (b) Supramolecular interactions I, II, III and IV. 


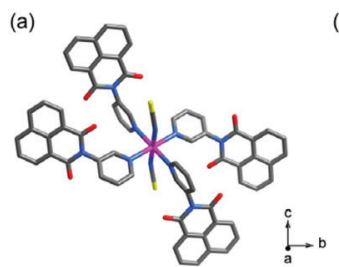

(c)

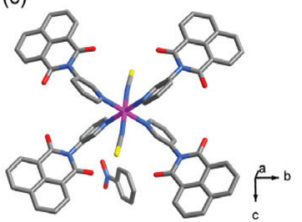

(b)

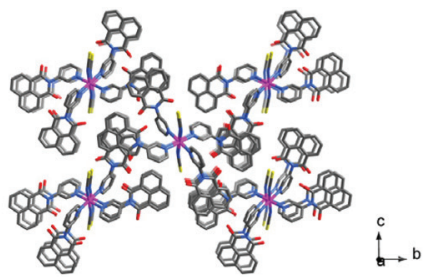

(d)

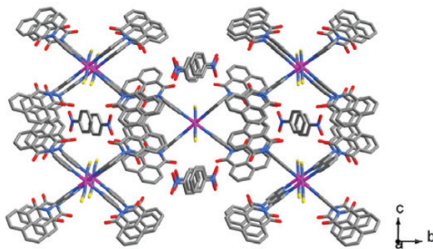

(e)

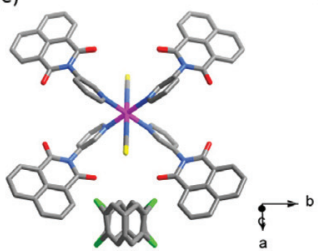

(f)

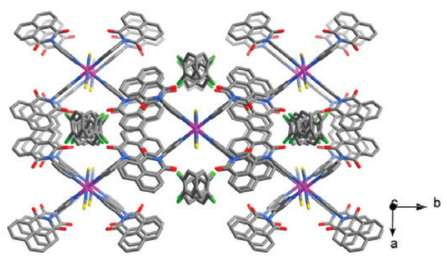

Fig. 3 Crystal structure of the: $\alpha$-phase of SAMM-5-Co-NCS representing (a) the coordination environment around Co ${ }^{2+}$ cations; (b) crystal packing of SAMM-5-Co-NCS molecules viewed along the a-axis; $\delta$-phase of SAMM-5-Co-NCS-NB representing (c) the coordination environment around $\mathrm{Co}^{2+}$ cations; (d) crystal packing viewed along the a-axis; $\delta$-phase of SAMM-5-Co-NCS-(1,2-DCB) representing (e) the coordination environment around $\mathrm{CO}^{2+}$ centre; (f) view of the crystal packing through c-axis; $\delta$-phase of SAMM-5-Co-NCS-OX representing (g) the coordination environment around $\mathrm{Co}^{2+}$ centre; (h) view of the crystal packing through a-axis.

tinct conformations and crystal packing for each $\delta$-phase (Fig. 3c and g). Intermolecular interactions in both $\delta$-phases are governed by $\mathrm{CH} \cdots \pi$ and $\mathrm{CH} \cdots \mathrm{O}$ contacts as well as $\pi \cdots \pi$ stacking enabled by the structural flexibility of 5 (ESI $\dagger$ ). When single crystals of SAMM-5-Co-NCS·NB and SAMM-5-Ni-NCS·NB were stored at room temperature for two days they underwent polymorphic transformations from $P 2_{1} / n$ to $C 2 / m$ (Tables S3 and S4, ESI $\dagger$ ). Both polymorphs can also be classified as $\delta$-phases. In the $P 2_{1} / n$ phases, NB molecules lie within 1D channels (Fig. $3 \mathrm{c}, \mathrm{d}$ and $\mathrm{S} 17 \mathrm{a}, \mathrm{b} \dagger$ ) whereas in the $C 2 / m$ phases NB molecules are disordered inside the channels. SAMM-5-CoNCS.(1,2-DCB) was found to be isostructural to the $C 2 / m$ phases of NB clathrates with disordered 1,2-DCB molecules inside the channels (Fig. 3e, $f$ and Table S4, ESI + ).

\section{Investigation of the reversibility of phase transformations}

We next investigated whether or not the $\delta$-phase (SAMM-5-CoNCS-NB) can revert back to the $\alpha$-phase (SAMM-5-Co-NCS) in a SC to SC phase transformation. Thermogravimetric Analysis (TGA) of the as-synthesised crystals of SAMM-5-Co-NCS-NB revealed a weight loss of $15 \%$ between 152 and $188^{\circ} \mathrm{C}$ consistent with the loss of two NB molecules per formula unit (Fig. 6). A single crystal of as-synthesised SAMM-5-Co-NCS-NB was heated at $185^{\circ} \mathrm{C}$ for $1 \mathrm{~h}$ to remove NB (process I, Fig. $4 \mathrm{a}$ and b). PXRD and SCXRD data from the single crystal obtained after heating were consistent with as-synthesised SAMM-5-CoNCS (Fig. 5 and Table S7, ESI†). Single crystals of SAMM-5-CoNCS as obtained from process I were then soaked in NB at $60{ }^{\circ} \mathrm{C}$ for $48 \mathrm{~h}$ (process II, Fig. $4 \mathrm{a}$ and b). The PXRD patterns of the single crystals obtained after soaking in NB matched well with the calculated and experimental PXRD patterns of as-synthesised SAMM-5-Co-NCS-NB (Fig. 5). TGA (Fig. 6) and SCXRD results also support the reversibility of process II (Fig. 4a and b and Table S7, ESI $\dagger$ ). A video recording of a single crystal of SAMM-5-Co-NCS in contact with liquid NB revealed evolution of bubbles from the crystal surface, which we attribute to the release of gases trapped in cavities during transformation from non-porous to porous phases (ESI†). SAMM-5-Co-NCS prepared from 5 and $\mathrm{Co}(\mathrm{NCS})_{2}$ in 1-butanol also formed SAMM-5-CoNCS.NB when soaked in NB at $60{ }^{\circ} \mathrm{C}$ for $48 \mathrm{~h}$ (process II)
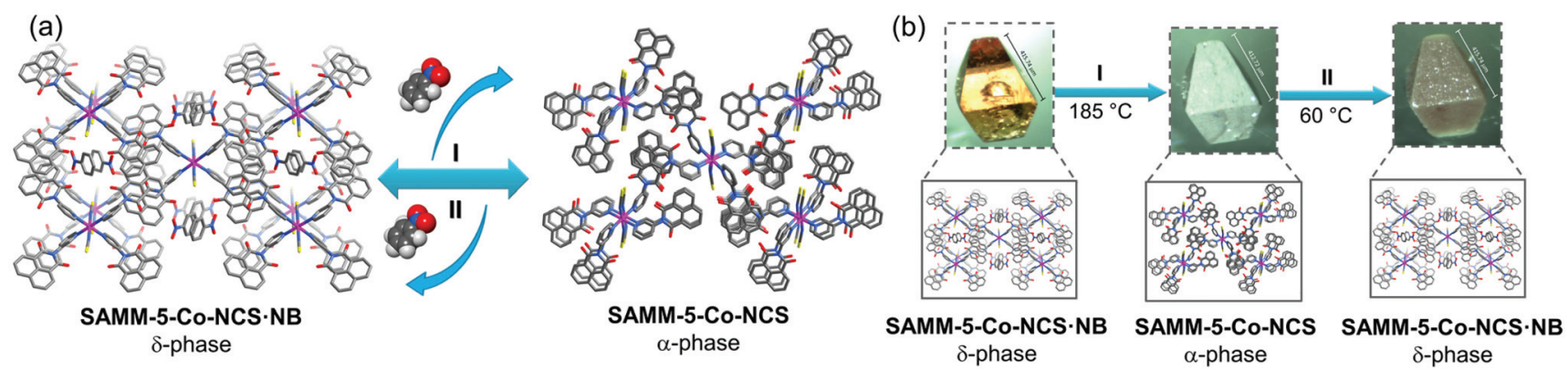

Fig. 4 (a) Reversible SC-SC phase transformation occurs upon heating single crystals of the $\delta$-phase SAMM-5-Co-NCS.NB at $185{ }^{\circ} \mathrm{C}$ to remove NB (process I, removal) followed by soaking crystals of the $\alpha$-phase SAMM-5-Co-NCS in NB to regenerate SAMM-5-Co-NCS-NB (process II, uptake). (b) Images of a single crystal subjected to processes I and II. 


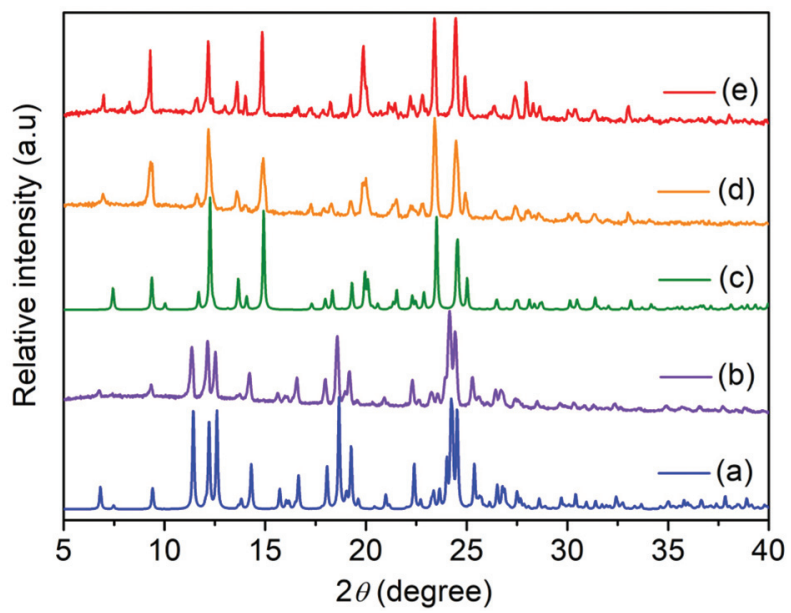

Fig. 5 PXRD pattern of (a) calculated SAMM-5-Co-NCS generated from SCXRD; (b) experimental SAMM-5-Co-NCS-NB after heating at $185^{\circ} \mathrm{C}$ resulting in $\alpha$-phase SAMM-5-Co-NCS; (c) calculated SAMM-5-CoNCS.NB generated from SCXRD; (d) experimental SAMM-5-Co-NCS.NB as-synthesised; and (e) SAMM-Co-NCS-NB obtained after soaking $\alpha$-phase SAMM-5-Co-NCS in NB at $60{ }^{\circ} \mathrm{C}$ resulting in $\delta$-phase.

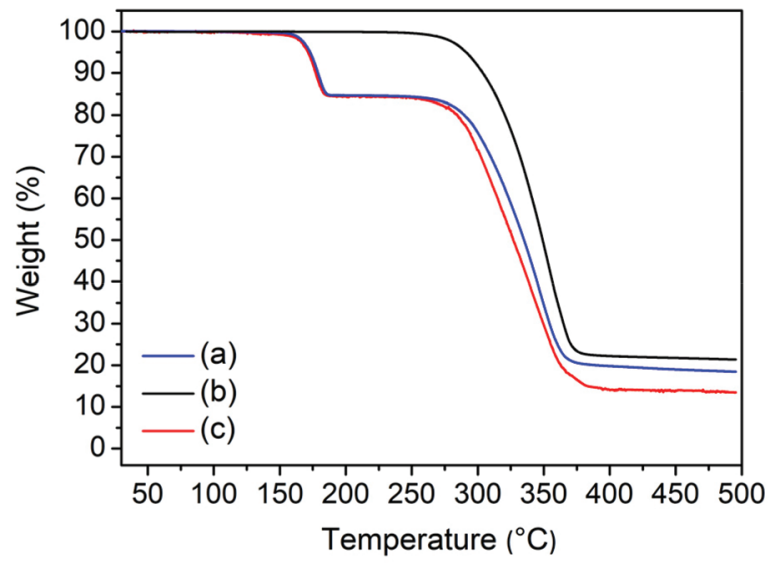

Fig. 6 TGA of the (a) as-synthesised $\delta$-phase SAMM-5-Co-NCS-NB; (b) $\alpha$-phase SAMM-5-Co-NCS obtained by heating $\delta$-phase SAMM-5-Co-

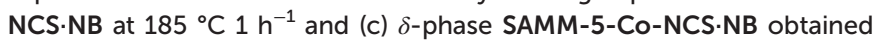
after soaking $\alpha$-phase SAMM-5-Co-NCS in NB at $60^{\circ} \mathrm{C} 48 \mathrm{~h}^{-1}$.

(Fig. S20, ESI $\dagger$ ). However, no phase transformation occurred following exposure of SAMM-5-Co-NCS to NB vapour at $60{ }^{\circ} \mathrm{C}$ for $48 \mathrm{~h}$ or after soaking in OX, MX, PX or EB at $60^{\circ} \mathrm{C}$ for $48 \mathrm{~h}$ (Fig. S21a, ESI $\dagger$ ). As-synthesised SAMM-5-Ni-NCS did not undergo phase transformation when soaked in $\mathrm{NB}$ at $60^{\circ} \mathrm{C}$ for $96 \mathrm{~h}$ or after soaking in OX, MX, PX or EB for $48 \mathrm{~h}$. PXRD revealed that SAMM-5-Ni-NCS remains after soaking in NB. (Fig. S21b and S22a, ESI $\dagger$ ). The $\delta$-phase SAMM-5-Ni-NCS·NB transformed to the $\alpha$-phase of SAMM-5-Ni-NCS upon heating at $185^{\circ} \mathrm{C}$ for $1 \mathrm{~h}$ (Fig. S21b and S22b, ESI $\dagger$ ). SAMM-5-Ni-NCS did not undergo a reversible phase transformation upon soaking in liquid $\mathrm{NB}$ at $60^{\circ} \mathrm{C}$ for $72 \mathrm{~h}$ as indicated by the TGA curve of a sample that had been soaked in NB (Fig. S21b and $\mathrm{S} 22 \mathrm{~b}, \mathrm{ESI} \dagger)$. Single crystals of the $\delta$-phase SAMM-5-Co-
NCS 1,2DCB prepared from 5, Co(NCS $)_{2}$ and 1,2-DCB transformed to SAMM-5-Co-NCS upon heating at $200{ }^{\circ} \mathrm{C}$ for $30 \mathrm{~min}$ (Fig. S23a ESI $\dagger$ ). The reverse structural transformation did not occur following soaking in 1,2-DCB at $60^{\circ} \mathrm{C}$ for $48 \mathrm{~h}$ according to TGA and PXRD data (Fig. S23a and b, ESI $\dagger$ ).

A single crystal of the $\delta$-phase SAMM-5-Co-NCS-OX prepared from 5, Co(NCS $)_{2}$ and OX transformed to SAMM-5-Co-NCS upon exposure to ambient conditions for $12 \mathrm{~h}$ (Table S7, ESI $\dagger$ ). This phase transformation can also be induced by heating crystals of SAMM-5-Co-NCS.OX and SAMM-5-Ni-NCS.OX at $200{ }^{\circ} \mathrm{C}$ for $1 \mathrm{~h}$, resulting in the formation of SAMM-5-Co-NCS and SAMM-5-Ni-NCS, respectively (Scheme S1, Fig. S9b, ESI $\dagger$ ). After heating, SAMM-5-Ni-NCS was washed with $\mathrm{MeOH}$ to remove residual 5, while SAMM-5-Co-NCS required no additional purification (Fig. S24, ESI $\dagger$ ). The reverse transformation did not occur following soaking of the regenerated phases of SAMM-5-Co-NCS and SAMM-5-Ni-NCS in OX at $60^{\circ} \mathrm{C}$ for 48 h. Rather, SAMM-5-Co-NCS and SAMM-5-Ni-NCS were isolated, respectively (Fig. S24, ESI $\dagger$ ). Therefore, among the Werner complexes reported herein, only the NB clathrate of SAMM-5-Co-NCS exhibited reversible transformations analogous to those seen in other Werner complexes and related coordination networks. ${ }^{56,57}$

\section{Structural flexibility of Werner complexes and the enclathration process}

The rotational freedom of the $\mathrm{Co}-\mathrm{N}$ bonds and the additional rotational freedom around the imide moiety is a feature of SAMM-5-Co-NCS that is evident from the structural results and could be key to enabling reversible transformations. ${ }^{11}$ Fig. $\mathrm{S} 25 \dagger$ reveals the torsion angles between the nitrogen atom from the pyridyl group and the $\mathrm{Co}^{2+}$ cation ( $\mathrm{Co}-\mathrm{N}$ bonds). For the $\alpha$-phase of SAMM-5-Co-NCS, there are two sets of torsion angles ranging from $8.27^{\circ}$ to $9.16^{\circ}$ and from $-80.13^{\circ}$ to $99.87^{\circ}$. In the $\delta$-phase SAMM-5-Co-NCS·NB, torsion angles about the $\mathrm{Co}-\mathrm{N}$ bond were found to range from $63.57^{\circ}$ to $-116.46^{\circ}$ and from $64.64^{\circ}$ to $115.36^{\circ}$. The $\delta$-phase of SAMM-5-Co-NCS-OX exhibits two sets of torsion angles ranging from $81.80^{\circ}$ to $98.20^{\circ}$ and from $57.69^{\circ}$ to $-122.31^{\circ}$ (Fig. S25, ESI $\dagger$ ). For the $\delta$-phase SAMM-5-Co-NCS.OX, one set of torsion angles about Co- $\mathrm{N}$ bonds $\left(-81.80^{\circ}\right.$ to $\left.98.20^{\circ}\right)$ are close to those encountered in the corresponding $\alpha$-phase SAMM-5-Co-NCS $\left(-80.13^{\circ}\right.$ to 99.87) (Fig. S25, ESI $\dagger$ ). Fig. S26 $\dagger$ reveals the torsion angles about the $\mathrm{C}-\mathrm{N}$ bond between pyridyl and imide group for each ligand of the Werner complex. In the $\alpha$-phase SAMM-5-Co-NCS, the torsion angles about $\mathrm{C}-\mathrm{N}$ bonds are $\pm 51.93^{\circ} / 129.89^{\circ}$ and $\pm 70.60^{\circ} / 109.80^{\circ}$. In the $\delta$-phase SAMM-5-Co-NCS·NB, the torsion angles about $\mathrm{C}-\mathrm{N}$ bonds are $\pm 60.74 \% 119.18^{\circ}$ and $\pm 63.27^{\circ} /$ $116.82^{\circ}$, while in the $\delta$-phase SAMM-5-Co-NCS.OX the torsion angles are twisted by $\pm 64.18^{\circ} / 114.50^{\circ}$ and $\pm 76.59^{\circ} / 101.74^{\circ}$.

\section{Conclusions}

In conclusion, ligand $\mathbf{5}$ was synthesised in high yield by mechanochemistry and formed new Werner complexes that 
can exist as $\delta$-phase Werner clathrates with channels that contain NB, 1,2-DCB or OX. Regarding the ligand, its potential for widespread use is good given that it is facile to prepare using simple and low-cost starting materials. Likewise, both the Werner complexes and the clathrates reported herein can be synthesised under mild conditions. A reversible transformation from the porous $\delta$-phase SAMM-5-Co-NCS·NB to its nonporous $\alpha$-phase SAMM-5-Co-NCS occurred via a SC-SC process, making it a rare example of a Werner clathrate that undergoes switching between non-porous and porous phases. Whereas earlier examples are known to readily undergo phase transformation via liquid or vapour contact with multiple guests, SAMM-5-Co-NCS transformed only in the presence of liquid NB. The isostructural analogue SAMM-5-Ni-NCS did not transform to its $\mathrm{NB}$ porous $\delta$-phase in the same manner. The torsion angles about $\mathrm{Co}-\mathrm{N}$ bonds or the $\mathrm{C}-\mathrm{N}$ bonds from the imide moiety in the structures of SAMM-5-Co-NCS.NB, SAMM-5-Co-NCS-OX and SAMM-5-Co-NCS can help to explain why SAMM-5-Co-NCS reversibly switches from porous to nonporous phase in the presence of NB, although it did not undergo any structural switching in the presence of the other guests. In the case of SAMM-5-Co-NCS-NB, enclathrated NB molecules induced higher structural distortion in the host compared to SAMM-5-Co-NCS-OX. The OX Werner clathrates exhibited one set of torsion angles analogous to the guest-free SAMM-5-Co-NCS, which means that the OX molecules induced smaller structural distortion, resulting in an irreversible adsorption process in SAMM-5-Co-NCS. We consider that the inherent torsional flexibility of the Werner complex with respect to its Co- $\mathrm{N}$ bonds and the ligand with respect to its imide moiety play important roles in enabling the observed reversible phase transformation.

\section{Experimental section}

\section{General aspects}

Reagents and solvents were purchased from Sigma-Aldrich, Fluorochem, Alpha or TCL and used without further purification. $\mathrm{C}^{3} \mathrm{~S}^{3}$ reaction was performed using agate mortar and pestle. ${ }^{1} \mathrm{H}$ and ${ }^{13} \mathrm{C}$ Nuclear Magnetic Resonance (NMR) spectra of 5 were recorded on a Jeol ECX400 at a frequency of 400 and $100 \mathrm{MHz}$, respectively. PXRD of the Werner complexes, clathrates and the reversible phase transformation in SAMM-5-CoNCS-NB to SAMM-5-Co-NCS were acquired on Empyrean diffractometer (PAN-analytical, Philips) using CuK $\alpha(\lambda=1.54178 \AA)$ source. PXRD data of 5, (SAMM-5-Co-NCS and SAMM-5-Ni-NCS after soaking in OX) and (SAMM-5-Co-NCS after removal and soaking in 1,2-DCB) were acquired on Proto AXRD Benchtop Powder Diffractometer. TGA curves were performed on a TA Instrument Q50 TG under flow of $\mathrm{N}_{2}$ with heating rate of $10{ }^{\circ} \mathrm{C}$ $\mathrm{min}^{-1}$. The balance purge was $40 \mathrm{~mL} \min ^{-1}$ and the sample

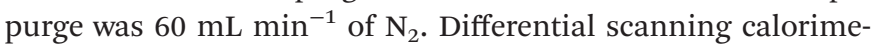
try (DSC) analyses were carried out on a TA Instrument DSC Q20 under a sample purge of $50 \mathrm{~mL} \min ^{-1}$ of $\mathrm{N}_{2}$ with the heating rate of $10{ }^{\circ} \mathrm{C} \mathrm{min}^{-1}$ for all compounds. Fourier
Transform Infrared (FTIR) spectra of 5, Werner complexes and clathrates were collected on a PerkinElmer Spectrum 100 spectrometer with ATR accessory.

\section{X-ray crystallography}

Crystal structures of all compounds were determined by SCXRD using either MoK $\alpha$ or $\mathrm{CuK} \alpha$ radiation in either Bruker D8 Quest fixed-chi diffractometer equipped with Photon II or Photon 100 detector, respectively. The unit-cells, data reduction and absorption correction (multi-scan method) were conducted using APEX3 ${ }^{58}$ suit (Bruker) including SADABS software. $^{59}$ Space groups were determined using XPREP $^{60}$ implemented in APEX3. Structures were solved using intrinsic phasing method (SHELXT) ${ }^{61}$ and refined on F2 using nonlinear least-squares techniques with SHELXL ${ }^{62}$ contained in OLEX2 v1.2.8 programs packages. ${ }^{63}$ All non-hydrogen atoms were refined anisotropically. Hydrogen atoms were added to the structure in idealised positions and were further refined according to the riding model. All crystal structures have been deposited with the Cambridge Crystallographic Data Centre (CCDC 1995785-1995796 and 2065192).

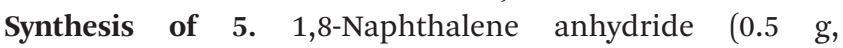
$2.52 \mathrm{mmol})$ and 3-amino-pyridine $(0.23 \mathrm{~g} ; 2.52 \mathrm{mmol})$ were ground until a homogeneous powder was obtained. Upon addition of $120 \mu \mathrm{L}$ of EtOH the resultant paste was further ground for 15 min until a free-flowing powder was obtained as intermediate. The yellow solid was heated at $185^{\circ} \mathrm{C}$ for $5 \mathrm{~h}$ to isolate $\mathbf{5}$. Ligand $\mathbf{5}$ was further purified by recrystallisation in $\mathrm{MeOH}$, in 93\% yield. Suitable crystals for SCXRD were obtained upon dissolving 5 in a 1:1 mixture of $\mathrm{CH}_{2} \mathrm{Cl}_{2}$ $(1.0 \mathrm{~mL})$ and $\mathrm{MeOH}(1.0 \mathrm{~mL})$. The final solution was sonicated for one min. Instantly suitable needles precipitated from the solution.

Synthesis of the $\alpha$-phase SAMM-5-Co-NCS. A solution of Co $(\mathrm{NCS})_{2}(6.4 \mathrm{mg}, 0.036 \mathrm{mmol})$ in $3.0 \mathrm{~mL}$ of hot butanol was added to a solution of 5 (40 $\mathrm{mg}, 0.145 \mathrm{mmol}$ ) dissolved in $3.0 \mathrm{~mL}$ of hot butanol. The vial was capped and heated in the oven at $60{ }^{\circ} \mathrm{C}$ for $24 \mathrm{~h}$. Pink crystals suitable for SCXRD were obtained in $89.30 \%$ yield (40.9 $\mathrm{mg}$ ).

Synthesis of the $\alpha$-phase SAMM5-Ni-NCS. A solution of Ni $(\mathrm{NCS})_{2}(6.4 \mathrm{mg}, 0.036 \mathrm{mmol})$ dissolved in $0.5 \mathrm{~mL}$ of hot methanol and $2.5 \mathrm{~mL}$ of butanol was added to a solution of 5 (40 mg, $0.145 \mathrm{mmol}$ ) dissolved in $3.0 \mathrm{~mL}$ of hot butanol. The vial was capped and heated in an oven at $60{ }^{\circ} \mathrm{C}$ for $24 \mathrm{~h}$. Green crystals suitable for SCXRD were obtained in $72.1 \%$ yield (33.0 mg).

Synthesis of the $\delta$-phase SAMM-5-Co-NCS·NB. A solution of $\mathrm{Co}(\mathrm{NCS})_{2}(6.4 \mathrm{mg}, 0.036 \mathrm{mmol})$ in $2.0 \mathrm{~mL}$ of hot butanol was added to a solution of 5 (40 $\mathrm{mg}, 0.145 \mathrm{mmol})$ dissolved in $2.0 \mathrm{~mL}$ of hot nitrobenzene. A navy blue solution was formed and the vial was capped and heated in an oven at $60{ }^{\circ} \mathrm{C}$ for 48 h. Pink crystals suitable for SCXRD were obtained in $51.2 \%$ yield (28.0 mg).

Synthesis of the $\delta$-phase SAMM-5-Ni-NCS.NB. A solution of $\mathrm{Ni}(\mathrm{NCS})_{2}(6.4 \mathrm{mg}, 0.036 \mathrm{mmol})$ dissolved in $0.5 \mathrm{~mL}$ of hot methanol and $1.5 \mathrm{~mL}$ of butanol was added to a solution of 5 
(40 mg, $0.145 \mathrm{mmol}$ ) dissolved in $2.0 \mathrm{~mL}$ of hot nitrobenzene. The vial was capped and heated in an oven at $60{ }^{\circ} \mathrm{C}$ for $48 \mathrm{~h}$. Green crystals suitable for SCXRD were obtained in $69.2 \%$ yield (37.8 mg).

Synthesis of the $\delta$-phase SAMM-5-Co-NCS-(1,2-DCB). A solution of $\mathrm{Co}(\mathrm{NCS})_{2}(6.4 \mathrm{mg}, 0.036 \mathrm{mmol})$ in $3.0 \mathrm{~mL}$ of hot butanol was added to a solution of 5 (40 $\mathrm{mg}, 0.145 \mathrm{mmol})$ dissolved in $3.0 \mathrm{~mL}$ of hot 1,2-dichlorobenzene (1,2 DCB). A navy blue solution was formed and the vial was capped and heated in an oven at $60{ }^{\circ} \mathrm{C}$ for $96 \mathrm{~h}$. Pink crystals suitable for singlecrystal X-ray diffraction were obtained in $28.5 \%$ yield (16.1 mg).

Synthesis of the $\delta$-phase SAMM-5-Co-NCS-OX. A solution of $\mathrm{Co}(\mathrm{NCS})_{2}(6.4 \mathrm{mg}, 0.036 \mathrm{mmol})$ in $2.0 \mathrm{~mL}$ of hot butanol was added to a solution of 5 (40 $\mathrm{mg}, 0.145 \mathrm{mmol})$ dissolved in $2.0 \mathrm{~mL}$ of hot $o$-xylene. A navy blue solution was formed and the vial was capped and stored at room temperature for $48 \mathrm{~h}$. Pink crystals were obtained in $54.8 \%$ yield $(29.3 \mathrm{mg})$.

Synthesis of the $\delta$-phase SAMM-5-Ni-NCS-OX. A solution of $\mathrm{Ni}(\mathrm{NCS})_{2}(6.4 \mathrm{mg}, 0.036 \mathrm{mmol})$ dissolved in $0.5 \mathrm{~mL}$ of hot methanol and $1.5 \mathrm{~mL}$ of butanol was added to a solution of 5 (40 mg, $0.145 \mathrm{mmol}$ ) dissolved in $1.5 \mathrm{~mL}$ of hot $o$-xylene. The vial was capped and heated at room temperature for $48 \mathrm{~h}$. Green crystals were obtained in $47.9 \%$ yield $(25.6 \mathrm{mg})$.

\section{Conflicts of interest}

There are no conflicts to declare.

\section{Acknowledgements}

We gratefully acknowledge Science Foundation Ireland (16/IA/ B2549, MJZ), the European Research Council (ADG 885695, MJZ), the Brazilian Federal Agency for Support and Evaluation of Graduate Education (CAPES) for a fellowship to Catiúcia R. M. O. Matos, the Brazilian agency National Council for Scientific and Technological Development (CMR, CNPq research fellowship grant number 313799/2017-2) and the Rio de Janeiro Research Foundation (FAPERJ, Cientistas do Nosso Estado grant number E-26/202.629/2019, CMR).

\section{Notes and references}

1 J. Lipkowski, in Inclusion Compounds: Structural Aspects of Inclusion Compounds Formed by Inorganic and Organometallic Host Lattices, ed. J. L. Atwood, J. E. D. Davies and D. D. MacNicol, Academic Press: London, 1984, vol. 1.

2 H. M. Powell, J. Chem. Soc., 1948, 61-73.

3 H. M. Powell and J. H. Rayner, Nature, 1949, 163, 566-567.

4 W. D. Schaeffer, W. S. Dorsey, D. A. Skinner and C. G. Christian, J. Am. Chem. Soc., 1957, 79, 5870-5876.

5 P. de Radzitzky and J. Hanotier, Ind. Eng. Chem. Process Des. Dev., 1962, 1, 10-14.

6 F. V. Williams, J. Am. Chem. Soc., 1957, 79, 5876-5877.
7 J. Lipkowski, L. Gluzinski, K. Suwinska and G. D. Andreetti, J. Inclusion Phenom., 1984, 2, 327-332.

8 P. Starzewski, W. Zielenkiewicz and J. Lipkowski, J. Inclusion Phenom., 1984, 1, 223-232.

9 D. R. Bond, G. E. Jackson and L. R. Nassimbeni, S. Afr. J. Chem., 1983, 36, 19-26.

10 M. H. Moore, L. R. Nassimbeni and M. L. Niven, J. Chem. Soc., Dalton Trans., 1987, 2125-2140.

11 L. R. Nassimbeni, M. L. Niven and M. W. Taylor, J. Coord. Chem., 1989, 19, 339-348.

12 L. Lavelle and L. R. Nassimbeni, J. Inclusion Phenom. Mol. Recognit. Chem., 1993, 16, 25-54.

13 L. R. Nassimbeni, M. L. Niven and M. W. Taylor, Inorg. Chim. Acta, 1987, 132, 67-73.

14 F. M. A. Noa, S. A. Bourne, H. Su and L. R. Nassimbeni, Cryst. Growth Des., 2017, 17, 1876-1883.

15 M. Lusi and L. J. Barbour, Chem. Commun., 2013, 49, 26342636.

16 M. Lusi and L. J. Barbour, Angew. Chem., Int. Ed., 2012, 51, 3928-3931.

17 J. Lipkowski, in Comprehensive Supramolecular Chemistry, ed. J. L. Atwood, J. E. D. Davies, D. D. MacNicol and F. Vogtle, Elsevier, Oxford, 1999, vol. 6.

18 M. M. Wicht, N. B. Báthori and L. R. Nassimbeni, Dalton Trans., 2015, 44, 6863-6870.

19 A. Y. Manakov, J. Lipkowski, K. Suwinska and M. Kitamura, J. Inclusion Phenom. Mol. Recognit. Chem., 1996, 26, 1-20.

20 J. Lipkowski and D. V. Soldatov, J. Inclusion Phenom. Mol. Recognit. Chem., 1994, 18, 317-329.

21 D. V. Soldatov and J. Lipkowski, J. Inclusion Phenom. Mol. Recognit. Chem., 1998, 30, 99-109.

22 D. V. Soldatov, V. A. Logvinenko, Y. A. Dyadin, J. Lipkowski and K. Suwinska, J. Struct. Chem., 1999, 40, 757-771.

23 D. V. Soldatov, G. D. Enright and J. A. Ripmeester, Cryst. Growth Des., 2004, 4, 1185-1194.

24 E. A. Ukraintseva, D. V. Soldatov and Y. U. A. Dyadin, J. Inclusion Phenom., 2004, 48, 19-23.

25 M. M. Wicht, H. Su, N. B. Báthori and L. R. Nassimbeni, CrystEngComm, 2016, 18, 2509-2516.

26 M. M. Wicht, L. R. Nassimbeni and N. B. Báthori, Polyhedron, 2019, 163, 7-19.

27 N. M. Sykes, H. Su, S. A. Bourne and L. R. Nassimbeni, Cryst. Growth Des., 2020, 20, 274-280.

28 S. Noro, T. Ohba, K. Fukuhara, Y. Takahashi, T. Akutagawa and T. Nakamura, Dalton Trans., 2011, 40, 2268-2274.

29 S. I. Noro, K. Fukuhara, K. Sugimoto, Y. Hijikata, K. Kubo and T. Nakamura, Dalton Trans., 2013, 42, 11100-11110.

30 Q. Y. Yang, P. Lama, S. Sen, M. Lusi, K. J. Chen, W. Y. Gao, M. Shivanna, T. Pham, N. Hosono, S. Kusaka, J. J. Perry, S. Ma, B. Space, L. J. Barbour, S. Kitagawa and M. J. Zaworotko, Angew. Chem., Int. Ed., 2018, 57, 56845689.

31 S. A. Allison and R. M. Barrer, J. Chem. Soc., 1969, 17171723.

32 S.-Q. Wang, S. Mukherjeea and M. J. Zaworotko, Faraday Discuss., 2021, DOI: 10.1039/D1FD00037C. 
33 A. M. Kałuża, S. Mukherjee, S.-Q. Wang, D. J. O'Hearn and M. J. Zaworotko, Chem. Commun., 2020, 56, 1940-1943.

34 M. Shivanna, K. Otake, J. Zheng, S. Sakaki and S. Kitagawa, Chem. Commun., 2020, 56, 9632-9635.

35 X. Tian, H. Zhou, X. Zhang, C. Wang, Z. Qiu, D. Zhou and J. Zhang, Inorg. Chem., 2020, 59, 6047-6052.

36 S.-Q. Wang, S. Mukherjee, E. Patyk-Kaźmierczak, S. Darwish, A. Bajpai, Q. Y. Yang and M. J. Zaworotko, Angew. Chem., Int. Ed., 2019, 58, 6630-6634.

37 S.-Q. Wang, Q. Y. Yang, S. Mukherjee, D. O’Nolan, E. PatykKaźmierczak, K. J. Chen, M. Shivanna, C. Murray, C. C. Tang and M. J. Zaworotko, Chem. Commun., 2018, 54, 7042-7045.

38 N. Kumar, S.-Q. Wang, S. Mukherjee, A. A. Bezrukov, E. Patyk-Kaźmierczak, D. O’Nolan, A. Kumar, M.-H. Yu, Z. Chang, X.-H. Bu and M. J. Zaworotko, Chem. Sci., 2020, 11, 6889-6895.

39 H. Kanoh, A. Kondo, H. Noguchi, H. Kajiro, A. Tohdoh, Y. Hattori, W. C. Xu, M. Inoue, T. Sugiura, K. Morita, H. Tanaka, T. Ohba and K. Kaneko, J. Colloid Interface Sci., 2009, 334, 1-7.

40 H. Kajiro, A. Kondo, K. Kaneko and H. Kanoh, Int. J. Mol. Sci., 2010, 11, 3803-3845.

41 G. B. Gardner, D. Venkataraman, J. S. Moore and S. Lee, Nature, 1995, 374, 792-795.

42 P. Willett, J. C. Cole and I. J. Bruno, CrystEngComm, 2020, 22, 7233-7241.

43 M. L. Cheney, G. J. McManus, J. A. Perman, W. Zhenqiang and M. J. Zaworotko, Cryst. Growth Des., 2007, 7, 616-617.

44 R. Sanii, A. Bajpai, E. Patyk-Kaźmierczak and M. J. Zaworotko, ACS Sustainable Chem. Eng., 2018, 6, 14589-14598.

45 R. Sanii, C. Hua, E. Patyk-Kaźmierczak and M. J. Zaworotko, Chem. Commun., 2019, 55, 1454-1457.

46 N. Shan, F. Toda and W. Jones, Chem. Commun., 2002, 2, 2372-2373.

47 T. Friščić, A. V. Trask, W. Jones and W. D. S. Motherwell, Angew. Chem., Int. Ed., 2006, 45, 7546-7550.
48 G. A. Bowmaker, Chem. Commun., 2013, 49, 334-348.

49 M. L. Cheney, M. J. Zaworotko, S. Beaton and R. D. Singer, J. Chem. Educ., 2008, 85, 1649-1651.

50 Z. Wang, N. Liu, H. Li, P. Chen and P. Yan, Eur. J. Inorg. Chem., 2017, 2017, 2211-2219.

51 A. Bacchi, D. Capucci, A. Gatti, C. Loffi, M. Pioli, D. Rogolino, F. Terenziani and P. Pelagatti, ChemistrySelect, 2017, 2, 7000-7007.

52 D. Prat, O. Pardigon, H.-W. Flemming, S. Letestu, V. Ducandas, P. Isnard, E. Guntrum, T. Senac, S. Ruisseau, P. Cruciani and P. Hosek, Org. Process Res. Dev., 2013, 17, 1517-1525.

53 S. Wöhlert, T. Fic, Z. Tomkowicz, S. G. Ebbinghaus, M. Rams, W. Haase and C. Näther, Inorg. Chem., 2013, 52, 12947-12957.

54 E. Loukopoulos, B. Berkoff, K. Griffiths, V. Keeble, V. N. Dokorou, A. C. Tsipis, A. Escuer and G. E. Kostakis, CrystEngComm, 2015, 17, 6753-6764.

55 S. Suckert, L. S. Germann, R. E. Dinnebier, J. Werner and C. Näther, Crystals, 2016, 6, 1-17.

56 Y. Inubushi, S. Horike, T. Fukushima, G. Akiyama, R. Matsuda and S. Kitagawa, Chem. Commun., 2010, 46, 9229-9231.

57 R. Kitaura, K. Seki, G. Akiyama and S. Kitagawa, Angew. Chem., Int. Ed., 2003, 42, 428-431.

58 APEX3. Ver. 2017.3-0, Bruker AXS Inc., Madison, Wisconsin, USA, 2017.

59 L. Krause, R. Herbst-Irmer, G. M. Sheldrick and D. Stalke, J. Appl. Crystallogr., 2015, 48, 3-10.

60 XPREP. Ver. 2014/2, Bruker AXS Inc., Madison, Wisconsin, USA, 2014.

61 G. M. Sheldrick, Acta Crystallogr., Sect. A: Found. Adv., 2015, C71, 3-8.

62 G. M. Sheldrick, Acta Crystallogr., Sect. C: Struct. Chem., 2015, C71, 3-8.

63 O. V. Dolomanov, L. J. Bourhis, R. J. Gildea, J. A. K. Howard and H. Puschmann, J. Appl. Crystallogr., 2009, 42, 339-341. 